\title{
Editorial Policies
}

\author{
Lawrence W. Sherman ${ }^{1,2,3}$
}

Published online: 8 May 2017

(C) Springer International Publishing AG 2017

Objective The Cambridge Journal of Evidence-Based Policing publishes peerreviewed, scientifically rigorous original research, in clear and plain English, written by and for practitioners of evidence-based policing. Our primary aim is to promote evidence-based practices in policing. Our strategy is to publish the kind of research that can assist police professionals across the democratic world to reduce crime and harm in their communities, while increasing the legitimacy, legality, and fairness of their police agencies. Our policy is to broadly communicate the expansion and application of knowledge by both police professionals and scholars. Our priority is to publish research by the police, for the police, and for the people they serve, while serving the academic research community with rigorous research and theory testing across a wide variety of topics as a home for nurturing evidence-based policing.

Scope The Journal publishes important new findings and replications of research for targeting, testing, and tracking the use of police resources to make better decisions for better results.

Definition "Evidence-based policing" is the systematic practice of applying research to the making of decisions in policing. It is simultaneously a body of knowledge that can be applied in practice, and a body of knowledge about how to apply that knowledge in a wide range of strategic, tactical, organizational, and political contexts. Its primary focus is the use of quantitative research to inform decisions of three kinds:

- Targeting priorities for police resources based upon distributions and concentrations of crime, harm, injustice, illegitimacy, and insecurity, including breakdowns of problems

Lawrence W. Sherman

Lawrence.Sherman@crim.cam.ac.uk

1 Cambridge Centre for Evidence-Based Policing, Somersham House, Rectory Lane, Cambridgeshire PE28 3EL, UK

2 Institute of Criminology, University of Cambridge, Sidgwick Ave, Cambridge CB3 9DA, UK

3 Department of Criminology and Criminal Justice, 2220 Lefrak Hall, University of Maryland, College Park MD 20742, USA 
by times, days, seasons, places, areas, persons, situations, crimes, and incident categories as well as prediction methods that provide observable rates of error - whether they are derived from qualitative clinical assessments, checklists of predictors, or advanced "big data" algorithms including "random forests" and other pioneering methods.

- Testing police practices, through a variety of research designs for examining cause and effect, including randomized controlled trials, systematic reviews, algorithmic forecasting, meta-analyses, and other methods. Studies of both effectiveness and cost-effectiveness are welcome, focusing on accomplishing policing objectives with minimum force. We define "police practices" broadly to include all dimensions of policing, from operations to investigations, human resources, management, training, discipline, scheduling, use of technologies, communications, inter-agency partnerships, citizen and corporate co-production of security, accountability, political oversight, and many other topics.

- Tracking police actions, in relation to their measured outputs and outcomes, to inform and guide implementation with corrective feedback and interventions. There is special need for research on how feedback and corrections can be made most effective in delivering police practices that have been tested and found to be effective if provided with precision.

Qualitative and quantitative methods In addition, the Journal will publish qualitative, quantitative, or mixed-methods case studies of efforts to introduce evidence-based policing in police agencies around the world. We encourage descriptions of both successes and failures, with clear lessons drawn for improving the success of such efforts in the future.

The Journal relies substantially, but by no means exclusively, on the research done by police professionals enrolled in graduate degree courses of the Cambridge Police Executive Program (CPEP). The CPEP was founded in 1996 by the University of Cambridge Institute of Criminology to offer a part-time post-graduate course leading to the degree of Master of Studies in Applied Criminology and Police Management. Originally limited to students who were senior UK officers being trained to become Chief Police Officers, the course was opened to police leaders in all countries in 2005, and in 2014 to all ranks of both officers and civilian police analysts or educators. With over 150 current students, the course has over 1000 graduates, most of whom are still active in police service, in the UK, USA, Canada, Australia, New Zealand, Sweden, Denmark, Hong Kong, Trinidad and Tobago, the Netherlands, and Ireland. They serve as the core of a global social network supporting evidence-based policing, while the current and recent students serve as the core producers of a rapidly growing practitioner-led research literature.

Much of the original findings we publish come from the CPEP's 18,000-word master's theses, which report original research that contributes to police knowledge derived from the massive data assets of the students' police agencies. These Cambridge theses are all intensively peer-reviewed, then considered separately for publication in a more compact form in this Journal. A process of editing and revision then usually includes the thesis writer as first author, the thesis supervisor as second author, and often a data analyst or journal editor or other participating researcher as additional authors as appropriate to each article, prior to a final peer-review of the shortened final version of the research. 
The Journal welcomes and encourages original submissions from outside the CPEP as well. All manuscripts submitted are carefully reviewed, regardless of whether they have any prior connection to the Cambridge course or faculty members. First authors who are academics rather than "pracademics" or practitioners are encouraged to submit work that will improve police decision-making. The Journal strives to maintain a mix of author backgrounds, while aiming to become the premier outlet for police professionals who do research. As the UK's Prime Minister in our foundation year of 2017, Theresa May, said in a speech to police superintendents in 2012:

"We are not surprised when doctors publish papers in journals about the most effective way for dealing with an illness, or when a lawyer produces a paper setting out the ramifications of a particular piece of case law. If we are serious about developing professionalism in policing, I want to see police officers and staff doing the same. I want to see them publishing their own research that is peer reviewed, that helps others learn, that changes the way other communities are policed."

For Whom Is This Journal Published? The audience for which this Journal is written includes

- Police practitioners and analysts and those who recruit, train, and lead them

- Academic and independent researchers who teach or study policing

- Elected officials responsible for overseeing police agencies, and their staff

- Members of the diverse Societies of Evidence-Based Policing across the democratic world

Format The format of the Journal is similar to any other peer-reviewed journal reporting empirical research. While some articles might be shorter, many will have 5000-8000 words to describe the research question, data and methods, results, and implications. What makes the Journal highly readable is a departure from general practice: the editors frequently become co-authors, with a police practitioner as first author as often as possible - but with writing and scientific clarity enhanced by editors taking direct responsibility for the quality and reliability of the writing and data analysis.

Commentaries The Journal is willing to consider 1000 to 2000 -word articles that reanalyze or re-interpret findings reported in a prior issue of the Journal. Acceptance for publication depends on the criterion of whether the commentary offers a contribution to the readers' understanding of the issues.

Peer review process Each article submitted or invited that passes initial editorial screening is referred for two initial peer reviews. One review is done by an academic, who is asked to consider various issues in the quality of the research and its theoretical significance. The second review is done by a police practitioner with at least a master's degree, who comments especially on the clarity of the presentation as well as the practical significance of the findings for policing. Once the article is edited and 
shortened into the appropriate format, the final article is given a third peer review by a member of the Editorial Board. Where one of the three senior editors is a co-author of the final version, the final peer reviewer is always selected from among the editorial board and who is not among the three senior editors.

We are excited about the launch of this new Journal, and look forward to receiving your submissions, hearing your feedback, and advancing the conversation about research for evidence-based policing. To take full advantage of our research reports, as well as videos, podcasts, and related material, please accept our invitation to become an Associate of the Cambridge Centre for Evidence-Based Policing Ltd., by registering today at www.cambridge-ebp.net.

Lawrence W. Sherman

Cambridge Centre for Evidence-Based Policing, Somersham, Cambridgeshire, UK 